GEOLOGIC HISTORY

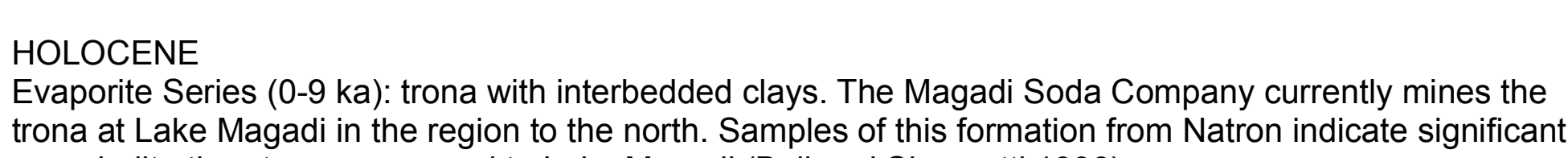
PLEISTOCENE

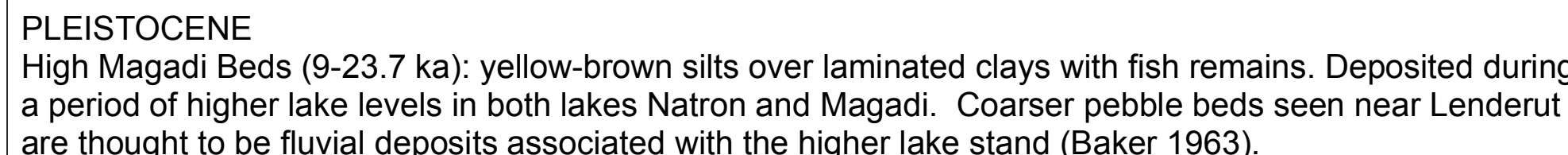

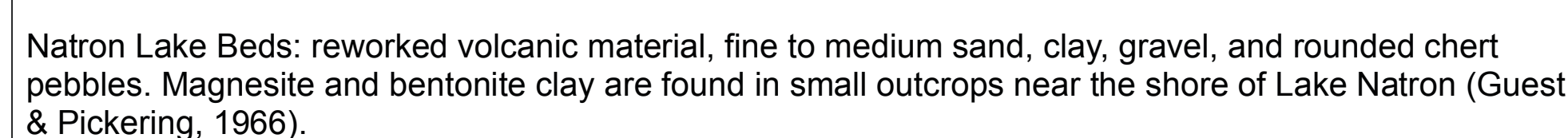

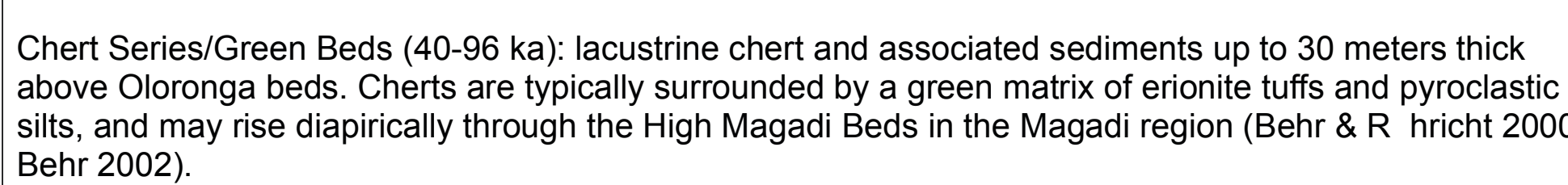

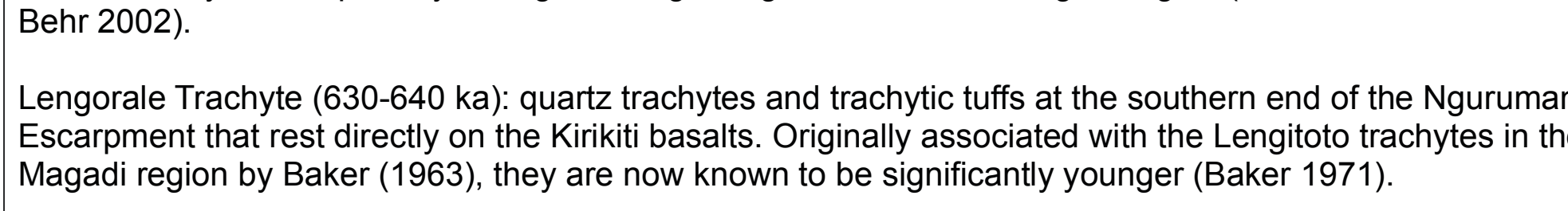

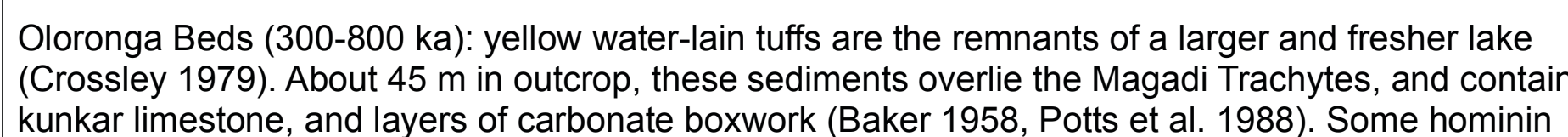

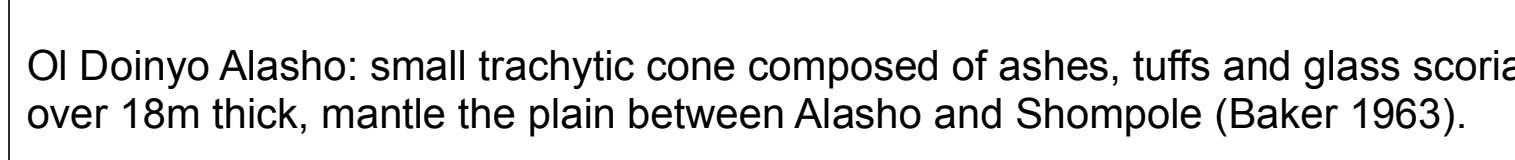

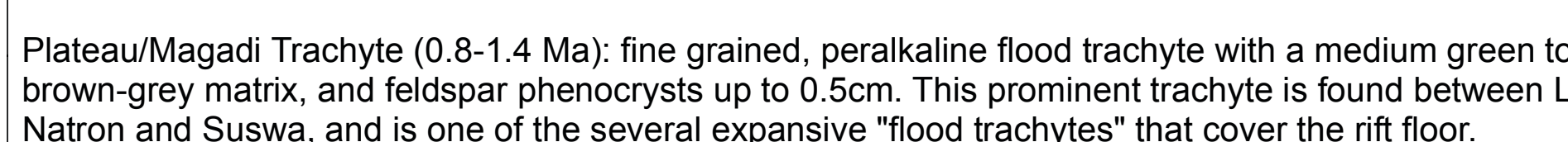

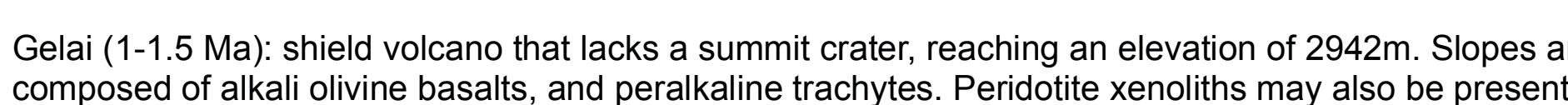

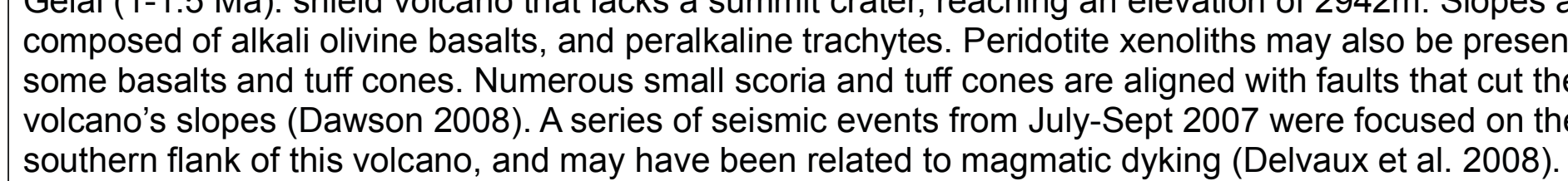
Shompole (Shombole) (1.196-2 Ma): highly we
carbonatitis and phonolites (Dauson 2008).

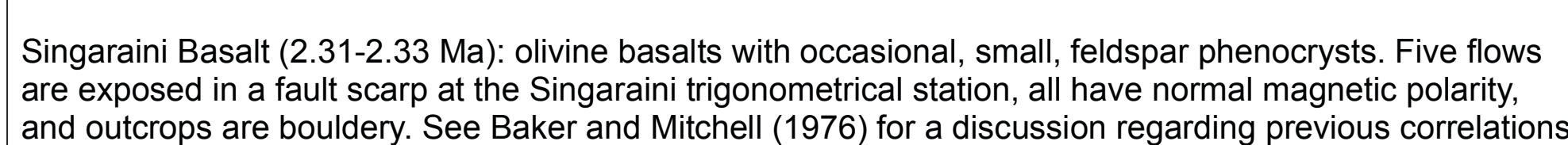

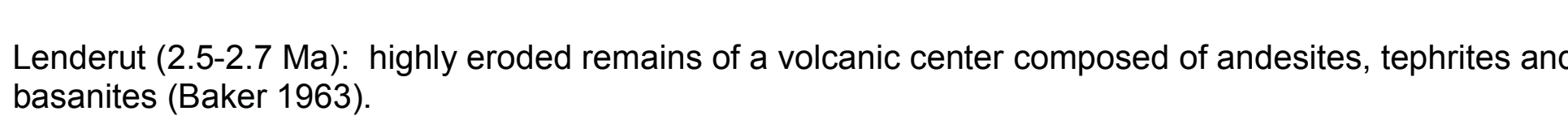

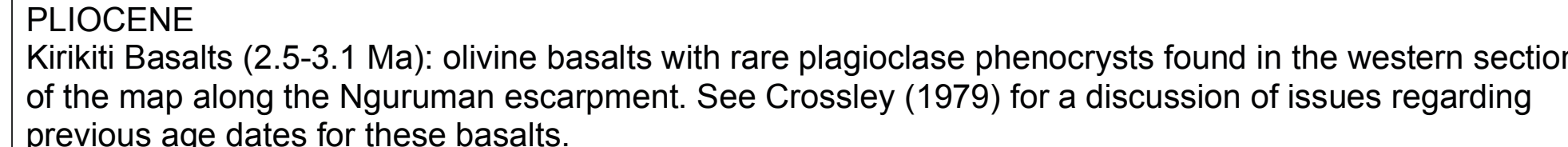
prevous age dates tor hthat
BASEMENT SYSTEM:

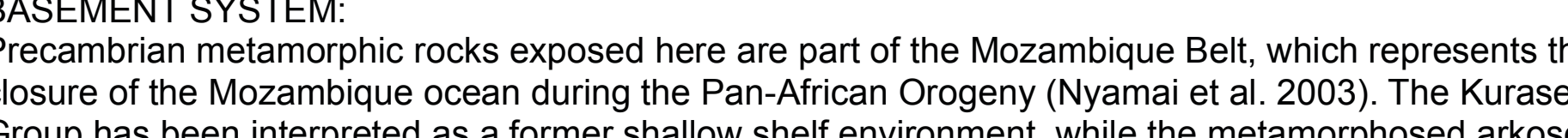

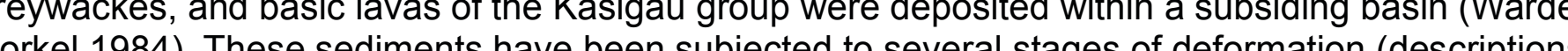
Warden \& Horkel 1984), with all but the mas

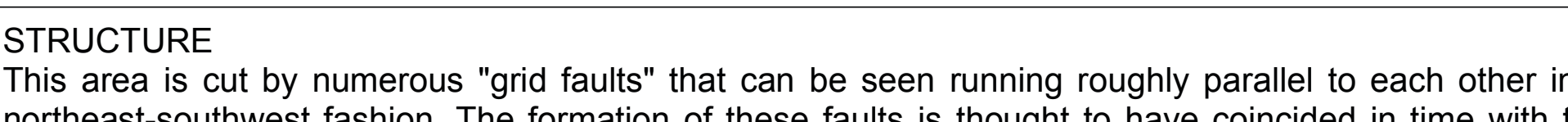

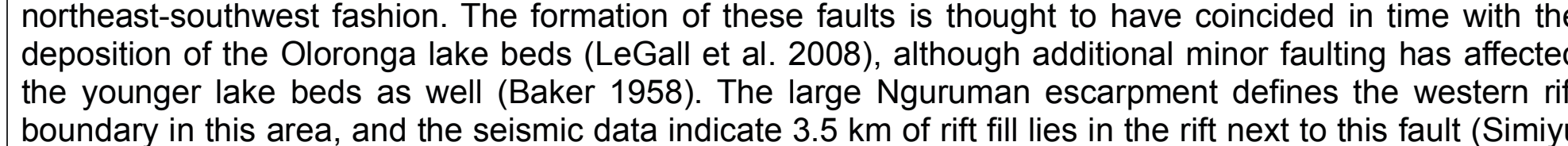

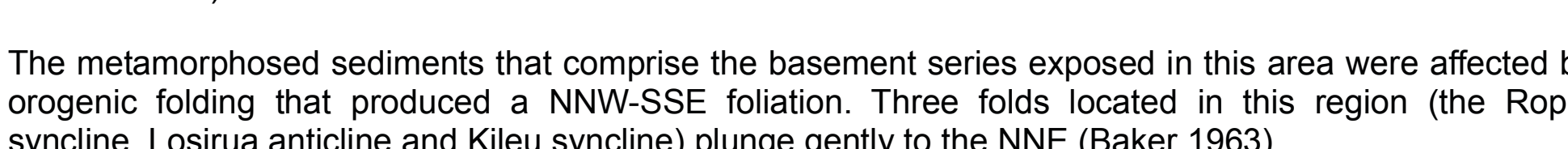

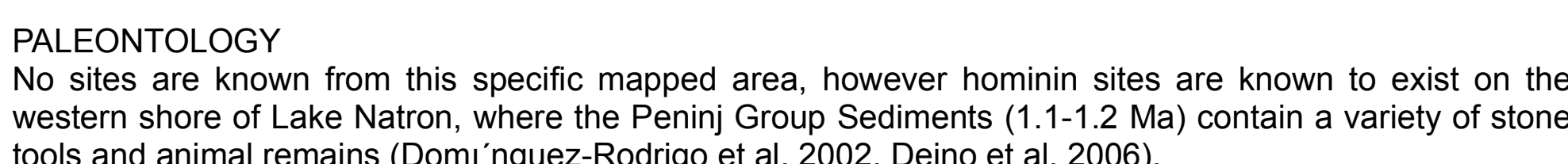

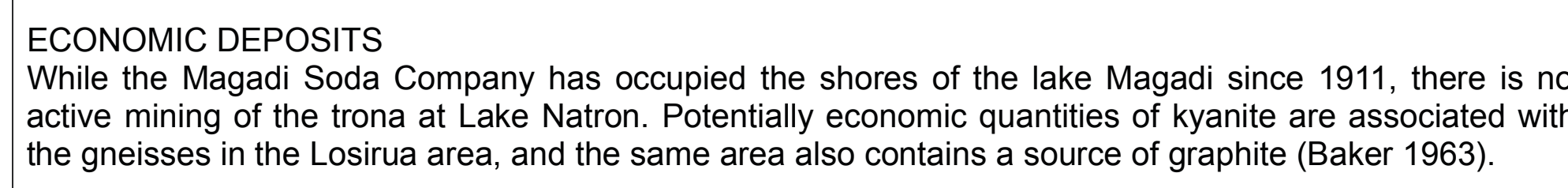

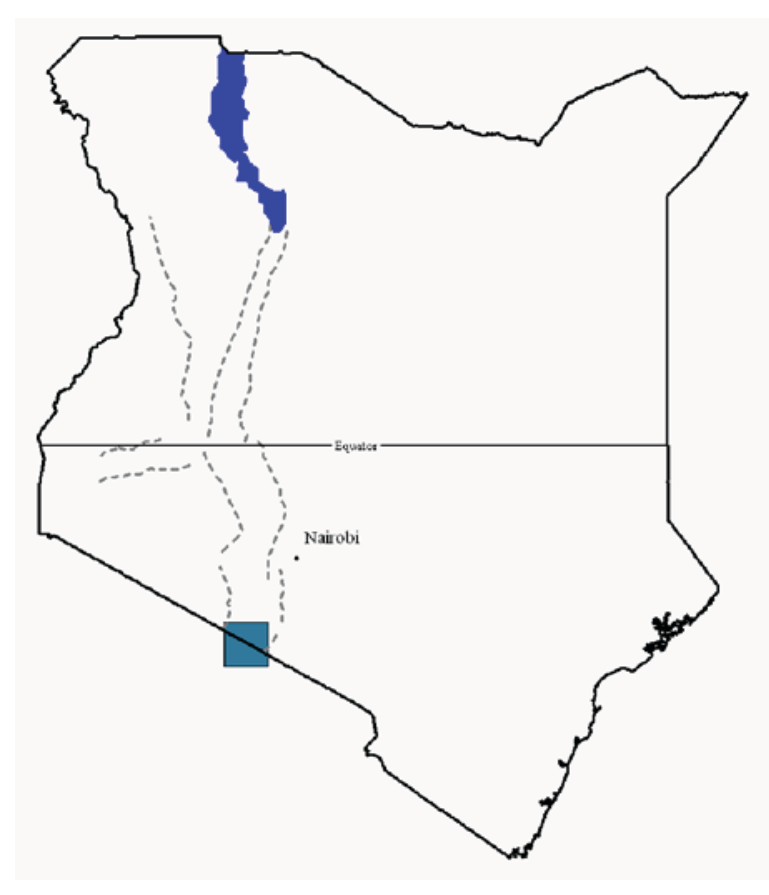

Cross Section Legend

$\square$ Lacustrine Sediments

Magadi Trachyte

Pratur Shompole

Singaraini

Pv Lenderut

\section{Geology of the Area South of Magadi, Kenya}
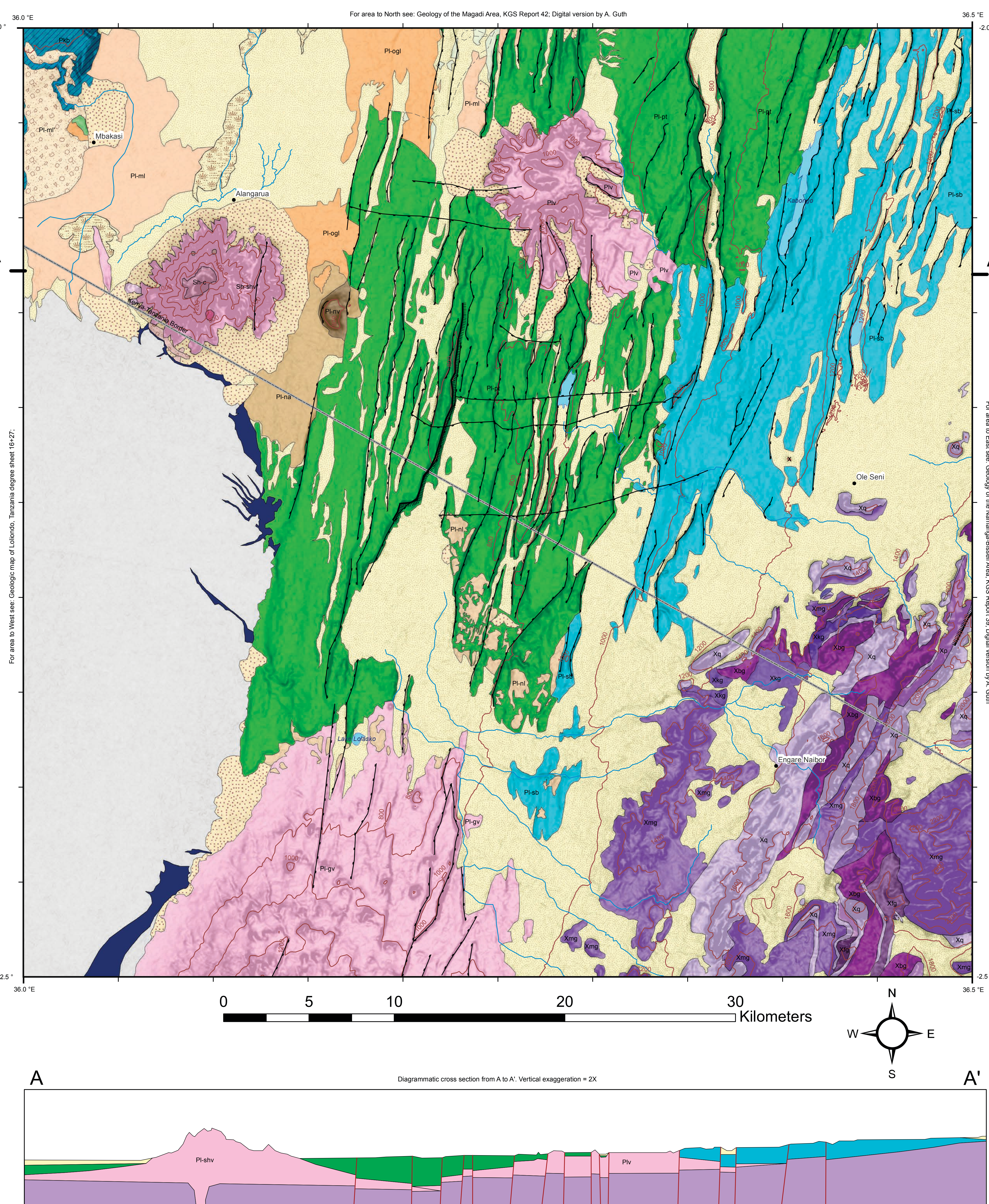

Legend

Sediments

Trona

Alluvial fan

Pleistocene

Fipl Pebble Bed

Priml High Magadi Beds

frool Oloronga Lake Beds

Prinl Natron Lake Beds

Volcanics

${ }^{\text {Pleistocene }}$

$A_{\text {Prutal Lengorale }}^{\prime}$

- faults-large

- faults-small

Prina Alasho ash

Agro Alasho centers

sine Magadi Trachyte

Shompole Volcanis

Prsan Shompole

stre Central vent depos

snnes Type III phonolite

sninez Type II phonolite

strom Type I phonolite

str.t. Carbonatite breccia

Pleistocene: Gelas

Pisto Singarain

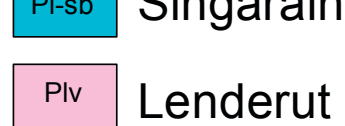

- City - Roadinar

- Coad-major — Lake- ephemeral

thers

Vowlla

- Road-minor rail

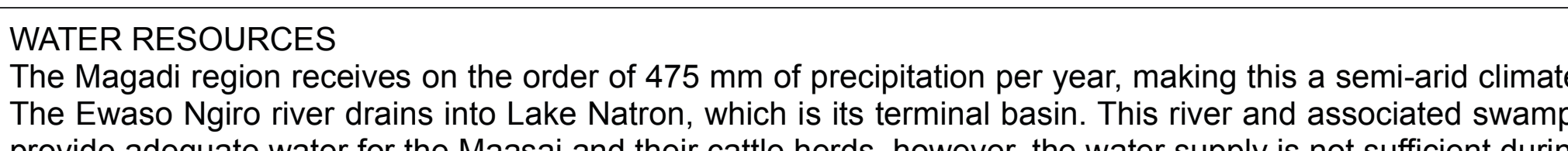

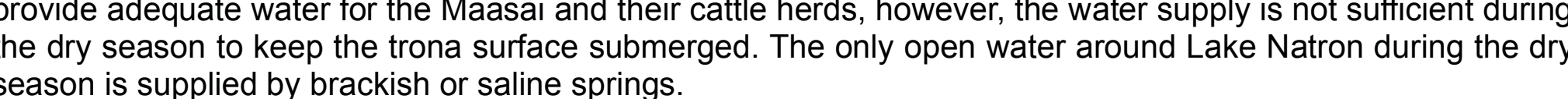
GEOTHERMAL PHENOMENA
The KenYa Ritt has a number
int

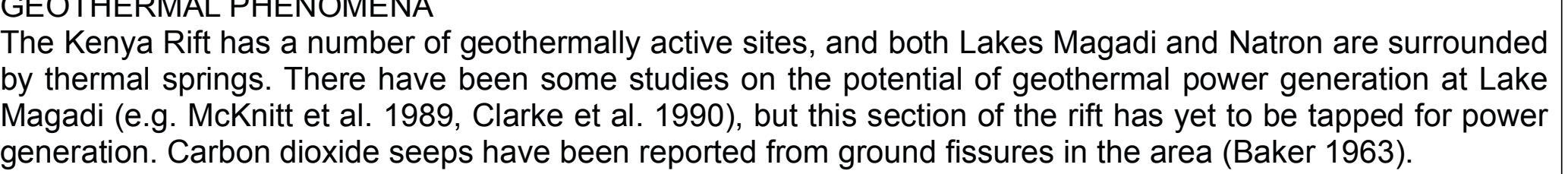
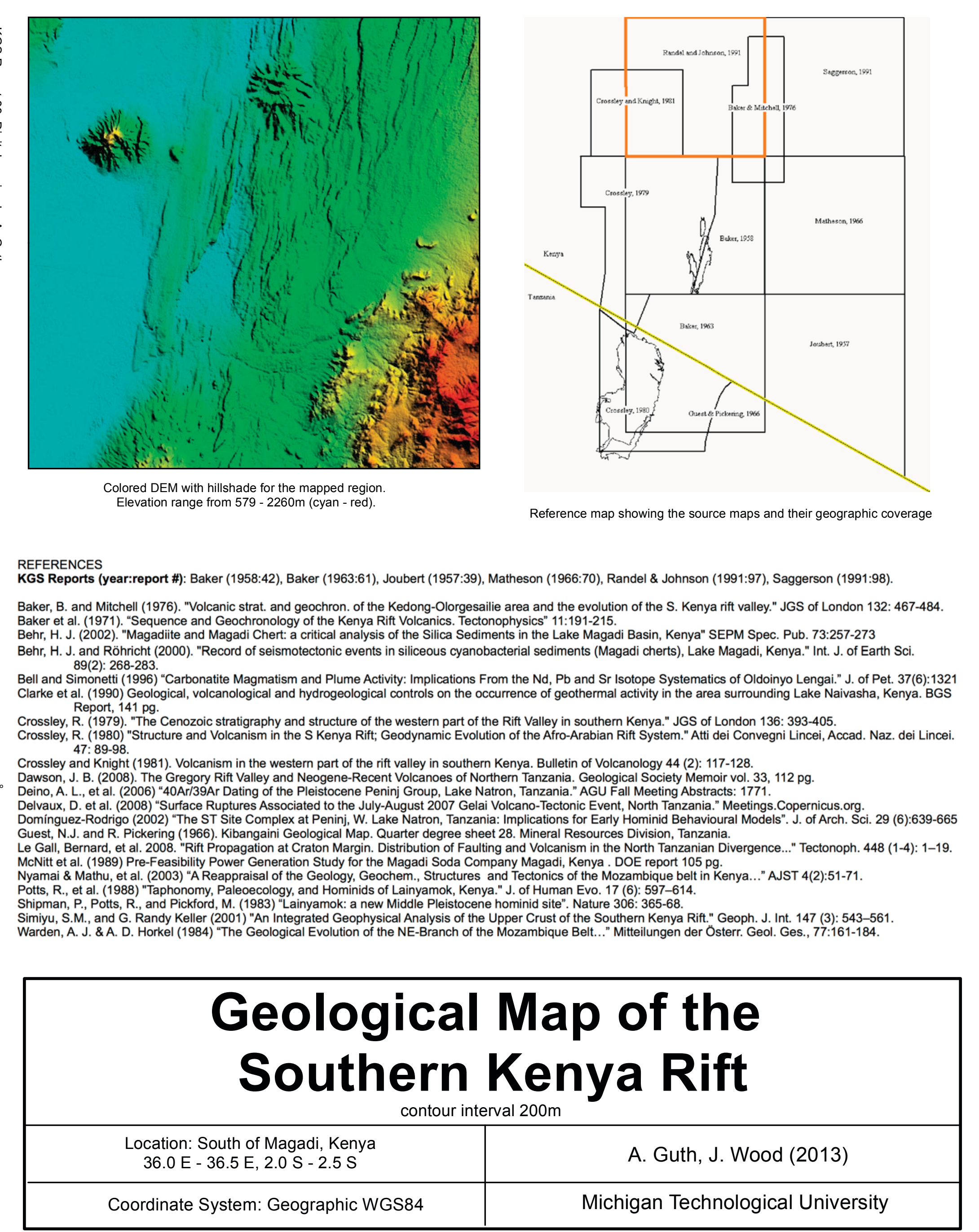